\title{
DÜBLIN
}

Technological University Dublin

ARROW@TU Dublin

\section{Dissipation of Pesticide Residues on Grapes and Strawberries Using Plasma-Activated Water}

\author{
Chaitanya Sarangapani \\ Technological University Dublin, chaitanyakrishna.sarangapani@tudublin.ie \\ Laurence Scally \\ Technological University Dulbin, laurence.scally@tudublin.ie \\ Miroslav Gulan \\ Technological University Dublin, miroslav.gulan@gmail.com
}

See next page for additional authors

Follow this and additional works at: https://arrow.tudublin.ie/schfsehart

Part of the Environmental Health and Protection Commons, and the Food Science Commons

\section{Recommended Citation}

Sarangapani, C., Scally, L., Gulan, M. et al. Dissipation of Pesticide Residues on Grapes and Strawberries Using Plasma-Activated Water. Food Bioprocess Technol 13, 1728-1741 (2020). DOI: 10.1007/ s11947-020-02515-9

This Article is brought to you for free and open access by the School of Food Science and Environmental Health at ARROW@TU Dublin. It has been accepted for inclusion in Articles by an authorized administrator of ARROW@TU Dublin. For more information, please contact arrow.admin@tudublin.ie, aisling.coyne@tudublin.ie, gerard.connolly@tudublin.ie.

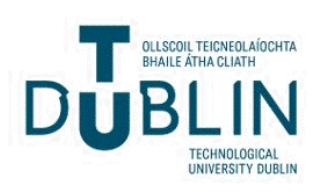


Authors

Chaitanya Sarangapani, Laurence Scally, Miroslav Gulan, and P. J. Cullen

This article is available at ARROW@TU Dublin: https://arrow.tudublin.ie/schfsehart/419 


\title{
Dissipation of Pesticide Residues on Grapes and Strawberries Using Plasma-Activated Water
}

\author{
Chaitanya Sarangapani ${ }^{1}$ - Laurence Scally ${ }^{1} \cdot$ Mirosalv Gulan $^{1} \cdot$ P. J. Cullen ${ }^{2,3}$ (I)
}

Received: 19 January 2020 / Accepted: 14 August 2020 / Published online: 20 August 2020

(C) Springer Science+Business Media, LLC, part of Springer Nature 2020

\begin{abstract}
In this study, we present a novel atmospheric air plasma discharge for the generation of plasma-activated water (PAW), with the aim of reducing pesticide residues on fresh fruit. For this purpose, a large discharge volume pin-to-plate cold plasma reactor was employed. The pesticide-spiked grapes and strawberries were processed with varying PAW concentrations to study their efficacies for pesticide degradation combined with an evaluation of any induced changes in key nutritional and quality attributes. The results suggest that the reduction of chlorpyrifos was $79 \%$ on grapes and $69 \%$ on strawberries while that of carbaryl was $86 \%$ on grapes and $73 \%$ on strawberries, respectively. The degradation of pesticides in PAW is due to the generation of metastable reactive species including nitrates, nitrites, and hydrogen peroxide. The high oxidation potential and acidic environment of this PAW are proposed as important actors for pesticide dissipation. In addition to the effective pesticide reductions obtained, there were no significant changes in the key physical attributes (color and firmness) of the treated samples and only slight changes in the ascorbic acid levels observed for both strawberries and grapes. This study points to the effective potential of PAW for chemical decontamination of fruit while maintaining important quality and nutritional parameters.
\end{abstract}

Keywords Plasma $\cdot$ Plasma-activated water $\cdot$ Pesticide degradation $\cdot$ Quality

\section{Introduction}

Pesticides are chemical compounds which are widely used in modern agriculture to control pests and delay crop spoilage. Pesticides have become an integral part of agriculture facilitating increased food production which is required to keep pace with the demand of growing global population and a reduced agricultural workforce. However, extensive use of pesticides poses a serious threat to both human health and the environment. Even low levels of pesticide residues in our food, particularly if consumed without washing or

P. J. Cullen

Patrick.cullen@sydney.edu.au

1 BioPlasma Research Group, School of Food Science and Environmental Health, Technological University Dublin, Dublin 1, Ireland

2 Centre for Advanced Food Enginomics, School of Chemical and Biomolecular Engineering, The University of Sydney, Sydney, Australia

3 Plasmaleap Technologies, Merewether Building, City Road, Sydney, Australia inadequate processing, may result in toxicity (Kamrin 1997). Consequently, effective methods of removing pesticide residues from fruits and plants are needed as intervention measures to prevent adverse effects on human health.

In order to minimize the potential risks associated with residual pesticide consumption, several methods have been used such as traditional flushing and chemical washes including sodium hypochlorite (Fett 2002), other chlorinated organic products (Allwood et al. 2004), hydrogen peroxide, organic acids (Yuk et al. 2006), ozonated water (Selma et al. 2007), and surfactants. However, these methods pose several disadvantages such as low removal efficacies of fat-soluble pesticides with traditional flushing, formation of by-products with chlorinated washes, which are potentially carcinogenic and mutagenic, and residues on irregular surfaces with surfactants (Han et al. 2006). Therefore, it is imperative to find an efficient and sustainable method for the removal of pesticide residues on fruits and fresh produce.

Recently, cold plasma has emerged as a novel processing technology for food preservation (Thirumdas et al. 2015). The effectiveness of cold plasmas for bio-decontamination, food packaging, and processing is 
increasingly being established (Sarangapani et al. 2018b). As a novel treatment technology, plasma offers several advantages by producing oxidizing species such as radicals (e.g., $\bullet \mathrm{H}_{1} \mathrm{O}_{2}{ }^{-} \cdot \mathrm{OH} \bullet$ ), molecules (e.g., $\mathrm{H}_{2} \mathrm{O}_{2}, \mathrm{O}_{2}$ ), and UV light (Sarangapani et al. 2017a). These species are reported as the primary actors for decontamination and removal of organic and inorganic substances. Even though several trials have been carried out on fruit and vegetables for microbial decontamination (Bourke et al. 2017; Misra et al. 2014b; Ziuzina et al. 2014), there are limited reports on the degradation of pesticides with cold plasma. Some studies of relevance include cold plasma pesticide degradation on solid surfaces (Bai et al. 2010), maize films (Feng et al. 2019), and fresh produce (Misra et al. 2014a; Phan et al. 2018).

Our group's research with atmospheric air plasma from dielectric barrier discharges (DBDs) showed effective pesticide degradation (Sarangapani et al. 2017c; Misra et al. 2014a). Misra et al. (2014a) reported that both direct and indirect plasma treatments result in the degradation of organic compounds. However, researchers have also reported that prolonged treatment times, especially with direct plasma treatment, can affect the nutritional attributes of fruits and vegetables (Picart-Palmade et al. 2018; Sarangapani et al. 2018b). In addition to the use of plasma gas treatment, cold plasma can also be used to generate plasma-activated water (PAW). In such processes, the plasma species generated interact with water, leading to changes in the water's chemical composition. These chemical changes include conductivity and redox potential, as well as the formation of an acidic environment and the production of high levels of reactive oxygen and reactive nitrogen species, resulting in strong anti-microbial conditions (Thirumdas et al. 2018). Boehm et al. (2016) reported on the relatively stable concentrations of reactive species in phosphate buffer saline solutions over a storage time of several weeks in a closed container. Based upon such findings, extensive research is being carried out on the efficacy of PAW for microbial reductions. Some studies have shown that the acidic environment is the primary driver for organic pollutant degradation, while others suggest that oxidation is the significant chemical step towards their degradation (Sarangapani et al. 2018a; Sarangapani et al. 2019). Importantly, the fluidity of PAW enables flow into the pores and surface crevices of agricultural products, allowing good contact with the target residue (Zheng et al. 2019). Thus, PAW is identified as a potential alternative to existing chemical washes.

In this study, we employ a novel PAW wash water technology and evaluate its effectiveness for the removal of pesticide residues of fresh fruit and also quantify any impact of the treatment on the nutritional and quality attributes of the produce.

\section{Materials and Methods}

\section{Materials}

Acetonitrile, methanol ( $\geq 99.9 \%$ capillary GC-grade), metaphosphoric acid, acetic acid and high purity $(>99.5 \%)$ carbaryl and chlorpyrifos standards (>95\%), gallic acid, and pelargonidin-3-glucoside standard were obtained from SigmaAldrich, Ireland. Fresh grapes and strawberries were purchased from the local supermarket (Dunnes stores, Dublin, Ireland) and stored under refrigerated conditions.

\section{Plasma-Activated Water Generation}

A novel large gap pin-to-plate plasma reactor was employed for this study. The reactor employs two steel plates as electrodes with the high voltage electrode consisting of a pin array $(11 \times 8)$ and the ground electrode consisting of a flat plate (PlasmaLeap Technologies, Sydney, Australia). The electrode pins form a slight convex pattern with the central pins closer to the ground electrode which supports a more homogenous plasma discharge across the array. For this experiment, the mean distance between the bottom of the pins and the ground electrode was $7 \mathrm{~cm}$ (Fig. 1). A high voltage power supply (Leap100, PlasmaLeap Technologies, Sydney, Australia) was employed to generate a plasma discharge in atmospheric air between the electrodes with a resonant frequency of $55.51 \mathrm{kHz}$ and at a discharge voltage (Vpp) of $32 \mathrm{kV}$ as shown in Fig. 1. The duty cycle was kept at $72 \mu$ s with the discharge frequency set to $1 \mathrm{kHz}$. The input power at these parameter settings was $5.66 \mathrm{~W}$. A detailed description of the working principle of this pin reactor has been provided previously (Scally et al. 2018). Optical emission spectroscopy was employed to characterize the plasma discharge operating in open air. For the generation of PAW, a petri dish containing deionized water $(25 \mathrm{~mL})$ was placed directly in the discharge on the ground electrode (Fig. 1) and subjected to plasma treatments for 5, 10, 20, and 30 min and termed as PAW-5, PAW10, PAW-20, and PAW-30 respectively.

\section{Physicochemical Property Measurement of PAW}

The conductivity of the effluent was measured using a conductivity meter (model CON-BTA, Vernier Software \& Technology Inc.) at ambient temperature $\left(16^{\circ} \mathrm{C}\right)$. The $\mathrm{pH}$ of the samples was measured using a calibrated glass electrode ORION pH meter (model 420A, Thermo Fisher Scientific Inc.). Oxidation reduction potential was measured by using a Hach Sension+ MM110, sensor. Reactive oxygen species (ROS) and reactive nitrogen species (RNS) concentrations were determined according to the procedure of $\mathrm{Lu}$ et al. (2017). 

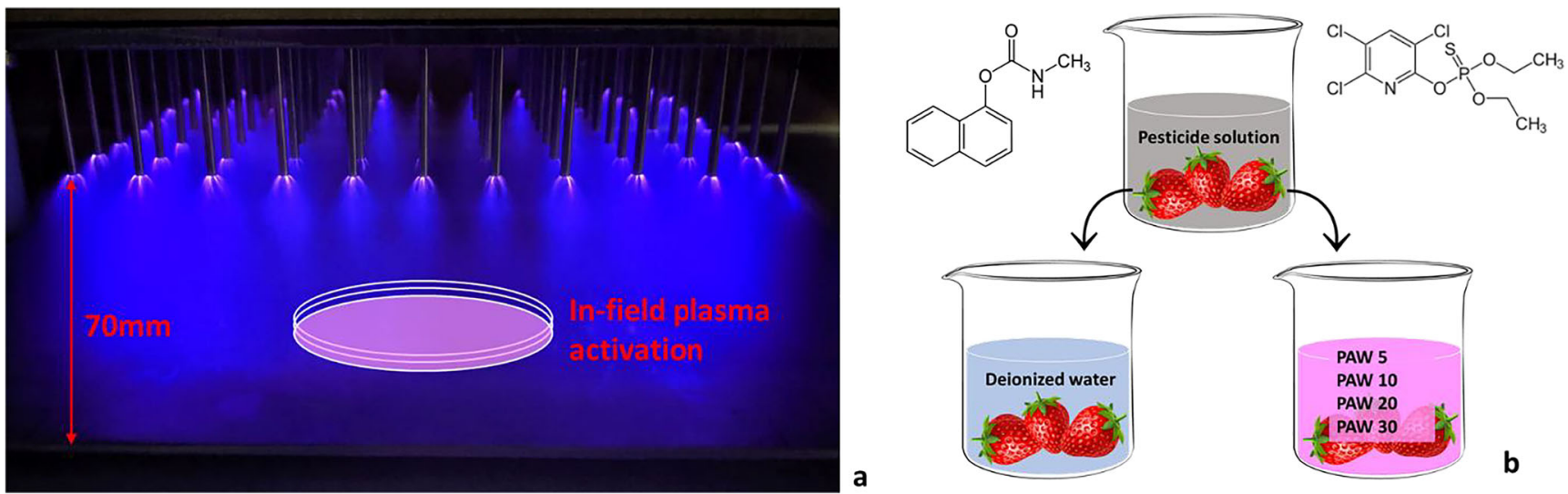

Fig. 1 Schematic of experimental setup. a The pin-to-plate atmospheric plasma discharge in open air for the direct treatment of water. b The steps for spiking and treatment of the fruit samples with the target pesticides

\section{Exposure of Samples to Pesticides}

Individual pesticide standards of both carbaryl and chlorpyrifos were prepared in methanol at $10 \mathrm{mg} / \mathrm{L}$ concentration. To ensure a homogeneous distribution of the pesticides on the sample surfaces, the samples were immersed into the pesticide solution for $30 \mathrm{~s}$ as per the technique described by Misra et al. (2014a). The samples were allowed to air dry under dark, and this dipping procedure was repeated for 3 times to ensure homogenous exposure to pesticides.

\section{PAW Treatment}

In order to investigate the efficacy of PAW treatment, the pesticide-spiked fruits were immersed in PAW water for 10 $\mathrm{min}$. After soaking for $10 \mathrm{~min}$, these samples were dipped into $100 \mathrm{~mL}$ of deionized water (DI) for $30 \mathrm{~s}$ followed by air drying.

\section{Extraction of Pesticides and Quantification}

Briefly, $10 \mathrm{~g}$ of the homogenized fruit samples was weighed into a $50-\mathrm{mL}$ centrifuge tube to which $12 \mathrm{~mL}$ of acetonitrile was added. These tubes were shaken for 5 min using a minimax to which $1 \mathrm{~g} \mathrm{NaCl}$ and $4 \mathrm{~g}$ of magnesium sulfate were added and shaken for $1 \mathrm{~min}$. This mixture was then centrifuged for $5 \mathrm{~min}$ at $3500 \mathrm{rpm}$. The homogenate was decanted into a $10-\mathrm{mL}$ centrifuge tube to which $0.15 \mathrm{~g}$ PSA and $0.5 \mathrm{~g}$ of $\mathrm{C}_{18}$ sorbent were added and vortexed for $1 \mathrm{~min}$. After this, the tubes were centrifuged for $5 \mathrm{~min}$ at $3500 \mathrm{rpm}$. Then, $1 \mathrm{~mL}$ of supernatant was taken and filtered using a 0.2- $\mu \mathrm{m}$ PTFE syringe filter into glass vials for further analysis.

The quantification of pesticides was determined using a Waters 600 HPLC system. The HPLC system was connected to a Waters 996 PDA detector and Waters auto-sampler (Waters, Ireland). The pesticide separation was carried out on a Phenomenex Gemini-Nx C18 column (Phenomenex,
UK), $5 \mu \mathrm{m}$ particle size $(250 \mathrm{~mm} \times 4.6 \mathrm{~mm})$. The mobile phase consisted of $70 \%$ acetonitrile and $30 \%$ water, with a flow rate of $0.6 \mathrm{~mL} / \mathrm{min}$. The detector wavelength was set in the range $210-400 \mathrm{~nm}$. Chromatographic data was collected and processed using the Empower2 software (Waters, Ireland). GC-MS analysis was performed to analyze the intermediate and final degradation products. A Varian $3800 \mathrm{GC}$ (JVA analytical Ltd. Ireland) with a 2200 Varian ion trap MS was used to analyze the samples. The compounds present were identified based on correlation with commercial NIST libraries and spectral library of pure substances and available literature.

\section{Calibration Curve}

Standard curves for the tested pesticides were established using pesticide standard solutions ranging between 0.05 and $10 \mathrm{mg} / \mathrm{L}$. The coefficients of determination $\left(r^{2}\right)$ were 0.997 and 0.998 for carbaryl and chlorpyrifos, respectively.

\section{Evaluation of Quality Parameters of Fruits}

\section{Physical Quality Parameters}

Firmness An Instron texture analyzer (Instron 4302 Universal Testing Machine, Canton, MA, USA) was used to analyze the firmness of control and treated samples. The texturometer was mounted with a $500-\mathrm{N}$ load cell and equipped with a $2-\mathrm{mm}$ flat head stainless steel cylindrical probe which punctures the sample at a download speed of $200 \mathrm{~mm} / \mathrm{min}$ over a distance of $10 \mathrm{~mm}$. A single fruit was placed on the stage for each measurement (Sarangapani et al. 2017c). The maximum force $(\mathrm{N})$ required to puncture the sample was used as an indication of firmness. Data were analyzed using the Bluehill software (Misra et al. 2014b). The firmness of 3 fruits from each was individually measured and an average firmness value reported. 
Color Analysis, Total Soluble Solids, and Titratable Acidity Fruit color was analyzed using a HunterLab spectrophotometer using the parameters $L^{*}$ (lightness), $a^{*}$ (redness), and $b^{*}$ (yellowness). A D65 illuminant was used as a light source with $\mathrm{d} / 8^{\circ}$ geometry. A standard white plate was used to calibrate the spectrophotometer. A handheld refractometer (Brix meter) (Delta refractometer code 20-50 range 0-15\% sugar w/w, Bellingham \& Stanley Limited, England) was used to determine the total soluble solid (TSS) concentrations of fruits. For this purpose, a small amount of juice from the representative fruit samples was placed on the refractometer and the readings were taken. The titratable acidity (TA) was determined through titration of $10 \mathrm{~mL}$ of juice from a representative sample of fruits diluted in $50 \mathrm{~mL}$ of deionized water with $0.1 \mathrm{~N} \mathrm{NaOH}$ to an end point of $\mathrm{pH} 8.1$. In the present study, results were expressed as a percentage of citric acid equivalents.

\section{Chemical Quality Parameters}

Extraction of Bioactive Compounds The extraction of polyphenols from fruit samples was performed according to the procedure of Sarangapani et al. (2017b) with minor modifications. Briefly, $100 \mathrm{~g}$ of each fruit (grapes and strawberries) samples was blended for 1 min using a commercial hand blender (Nutribullet, UK). The blended fruits were placed in a conical flask containing $200 \mathrm{~mL}$ of $90 \%$ methanol as extraction solvent. This mixture was stirred for $20 \mathrm{~min}$ at room temperature using a magnetic stirrer. Subsequently, the samples were then filtered and centrifuged for $15 \mathrm{~min}$ at $4750 \mathrm{rpm}$. The supernatant was filtered and stored in the refrigerator at 3 ${ }^{\circ} \mathrm{C}$. After $3 \mathrm{~h}$, the crude extracts were collected and stored at 4 ${ }^{\circ} \mathrm{C}$ in the dark.

The determination of total phenolic content was analyzed to investigate any changes in chemical quality attributes of the treated produce. The determination of the total phenolic content of the fruits as described by Singleton et al. (1999) was followed in this study. A calibration curve was prepared using a standard solution of gallic acid $(0-10 \mathrm{ug} / \mathrm{mL})$. The results are expressed on a fresh weight (FW) basis as $\mathrm{mg}$ gallic acid equivalents (GAE)/100 g sample. The total flavonoid contents of fruits were determined using the method developed by Zhishen et al. (1999). A calibration curve was prepared using a standard solution of catechin. The results are expressed on a fresh weight (FW) basis as $\mathrm{mg}$ catechin equivalents (CEQ)/100 g samples. The ascorbic acid contents of the fruits were analyzed by HPLC using the method described by Misra et al. (2015).

\section{Statistical Analysis}

The results were statistically analyzed by two-way ANOVA using SPSS (IBM statistical analysis version 19), and the significance among the samples was compared at $p<0.05$ by the least significant difference post hoc comparison, SPSS 19 version. All the results represent the average of three separate experiments.

\section{Results and Discussion}

\section{Optical Emission Spectroscopy}

As observed from the optical emission spectroscopy (OES) spectra (Fig. 2), the discharge is principally dominated by the nitrogen $\mathrm{N}_{2}(\mathrm{C}-\mathrm{B})$ second positive system and $\mathrm{N}_{2}{ }^{+}$(B $-\mathrm{X})$ first negative system $(300-400 \mathrm{~nm})$ which is expected as air is used as the discharge gas. In addition, a small peak near (306-309 nm) was also observed which corresponds to $\mathrm{OH}(\mathrm{A}-\mathrm{X})$ which is formed due to the dissociation of water molecules. During the plasma discharge, the RNS species generated may have synergistic effects with ROS ( $\mathrm{Lu}$ et al. 2017). These results indicate that the discharge and generated PAW is a source of both RNS and ROS.

\section{Evaluation of the Physicochemical Properties of PAW}

The $\mathrm{pH}$ of the solution is considered to be an important parameter governing the degradation process. It can be observed from Fig. 3a that the $\mathrm{pH}$ of the PAW is significantly different $(p<0.05)$ to the control, with values falling from 6.16 to 2.86 after $30 \mathrm{~min}$ plasma treatment. This is attributed to the formation and accumulation of strong acids such as nitric acids, nitrous acid, and other carboxylic acids. It is known that atmospheric air plasma generates numerous oxygen species such as $\mathrm{O}_{3}, \cdot \mathrm{OH}$, and $\mathrm{H}_{2} \mathrm{O}_{2}$ by electron disassociation of oxygen and water molecules, followed by subsequent chemical reactions during the treatment and post treatment. It was also found that the conductivity increased with the treatment exposure due to generation of ionic species in the PAW. The conductivity of DI water was found to be $25 \mu \mathrm{S} / \mathrm{cm}$ which gradually increased $(p<0.05)$ to $325 \mu \mathrm{S} / \mathrm{cm}$ after $30 \mathrm{~min}$ of plasma treatment (Fig. 3b). Furthermore, the oxidation reduction potential was employed to evaluate the presence of reactive species and the oxidation properties of the PAW. The oxidation reduction potential (ORP) value of the DI water was $175 \mathrm{mV}$ with the $5 \mathrm{~min}$ PAW sample recording a value of $331 \mathrm{mV}$. Further, an increase in treatment exposure from 10 to $30 \mathrm{~min}$ increased the value by $35 \%$ (Fig. 3c). From these results, it can be concluded that the formed PAW consists of oxidative species in water post plasma treatment. Overall, the results of $\mathrm{pH}$, ORP, and conductivity also support the OES results.

RNS (nitrates and nitrites) and $\mathrm{ROS}\left(\mathrm{H}_{2} \mathrm{O}_{2}\right)$ concentrations in the PAW were also quantified and are presented in Fig. 4. The reactive species generated during plasma treatment undergo several chemical reactions to form ROS such as $\bullet \mathrm{OH}$ and $\mathrm{H}_{2} \mathrm{O}_{2}$ (Sarangapani et al. 2016). The concentrations of 
Fig. 2 Optical emission spectroscopy of plasma discharge

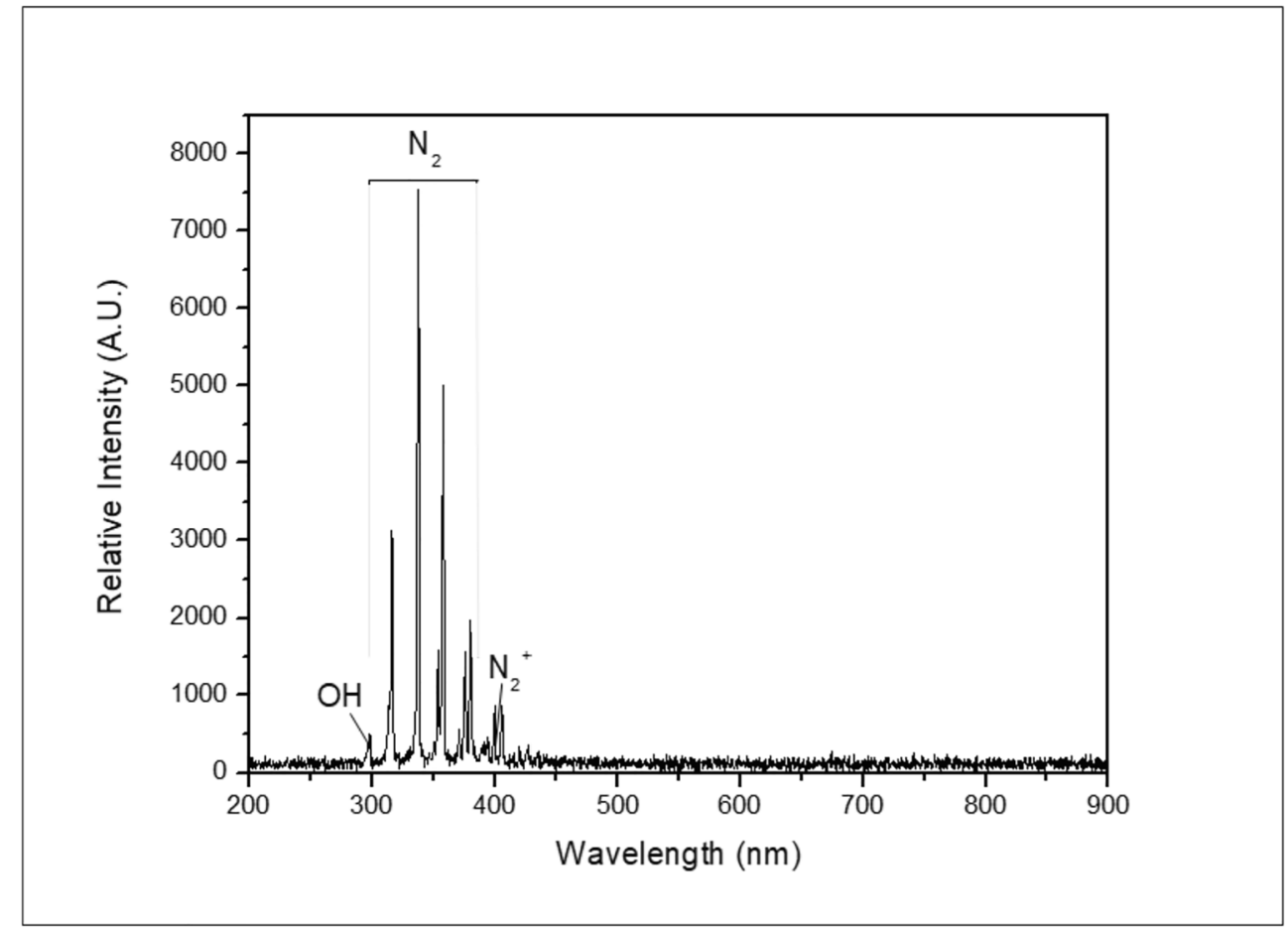

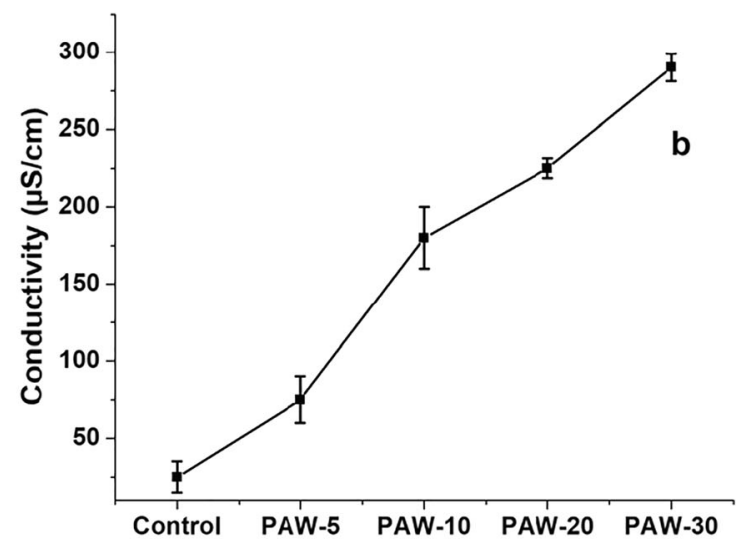

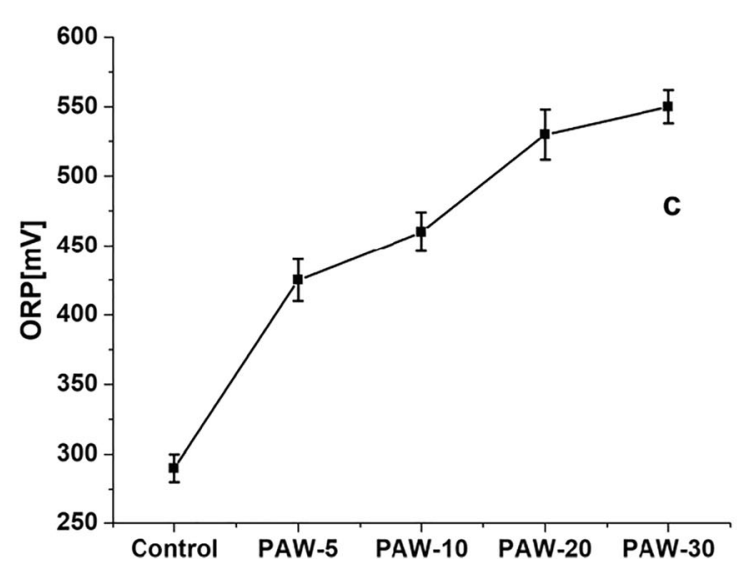

Fig. 3 Variations in a pH, b conductivity, and $\mathbf{c}$ ORP of plasma-activated water treated for 5,10, 20, and 30 min. Note: PAW-5, PAW-10, PAW-20, and PAW-30 refer to plasma-activated water (PAW) subjected to plasma treatment for 5, 10, 20, and 30 min respectively 

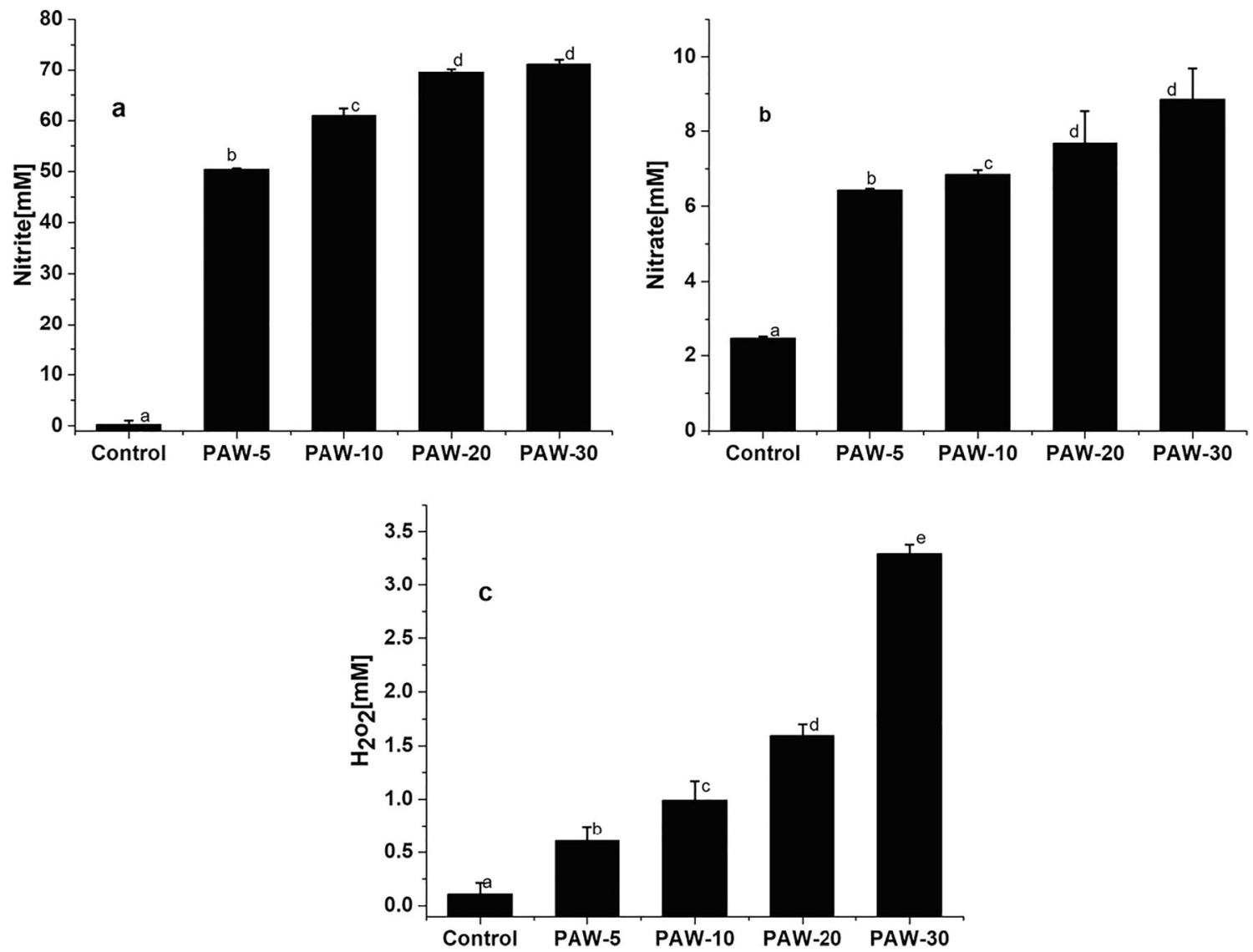

Fig. 4 Variation of nitrate, nitrites, and $\mathrm{H}_{2} \mathrm{O}_{2}$ concentrations in plasmaactivated water (PAW) treated for 5,10,20, and $30 \mathrm{~min}$. Mean values $(n=$ 3 ) with the different superscript letters are significantly different $(p<$ 0.05 ) and with the same superscript letters are not significantly different

$(p \geq 0.05)$. Note: PAW-5, PAW-10, PAW-20, and PAW-30 refer to plasma-activated water (PAW) subjected to plasma treatment for 5, 10, 20 , and 30 min respectively

$\mathrm{H}_{2} \mathrm{O}_{2}$ significantly increased $(p<0.05)$ with respect to PAW generation time. The retention of reactive species in the gas phase in contact with liquids results in high amounts of $\mathrm{H}_{2} \mathrm{O}_{2}$. Our group's earlier work achieved stable levels of $\mathrm{H}_{2} \mathrm{O}_{2}$ in PBS solutions for several weeks in a closed container (Boehm et al. 2016). Similarly, the amount of RNS (nitrates and nitrites) in PAW significantly $(p<0.05)$ increased with PAW generation from 5 to $30 \mathrm{~min}$. Such increases in RNS and ROS in water result in a significant $\mathrm{pH}$ drop. Several authors have reported that the oxidative ability of RNS is lower than ROS, as these react with stronger oxidant $\bullet \mathrm{OH}$ to form $\mathrm{HNO}_{3}$ (Jiang et al. 2014).

\section{Pesticide Degradation Efficacy of PAW}

To study the efficacy of PAW for pesticide degradation, the samples were treated with PAW for $10 \mathrm{~min}$ and analyzed using HPLC. The initial concentrations of pesticides observed on the grape samples were found to be $8.78 \mathrm{mg} / \mathrm{L}$ for chlorpyrifos and $9.35 \mathrm{mg} / \mathrm{L}$ for carbaryl. Similarly, the initial concentrations of pesticides observed on the strawberry samples were found to be $7.45 \mathrm{mg} / \mathrm{L}$ for chlorpyrifos and $8.45 \mathrm{mg} / \mathrm{L}$ for carbaryl. The removal efficiency by DI water was also compared with PAW treatment. From Fig. 5, it is evident that the removal efficiency was lower for DI water compared with PAW. Comparably, the concentration of residual pesticide concentration decreased significantly with exposure to PAW. For instance, treatment with PAW-30 resulted in a substantially more effective removal compared with PAW-5 treatment. The maximum removal efficiency of the pesticides after PAW-30 treatment of the grapes was found to be $79 \%$ for chlorpyrifos and $86 \%$ for carbaryl. Likewise, the maximum removal efficiencies on strawberries were found to be $69 \%$ for chlorpyrifos and $73 \%$ for carbaryl. The difference in the removal of pesticides is due to differences in the chemical structures of pesticides (Jiang et al. 2014; Sarangapani et al. $2018 b)$. It is known that carbaryl belongs to carbamates where chlorpyrifos is an organophosphate pesticide. Several studies have reported that the chemical structure of pesticide is the dominant factor for the persistence because it influences the chemical stability during the degradation reaction. The difference in degradation is due to difference in electronegativity and bond energies. Also, the difference in the surfaces between the grapes and strawberries will influence the process 

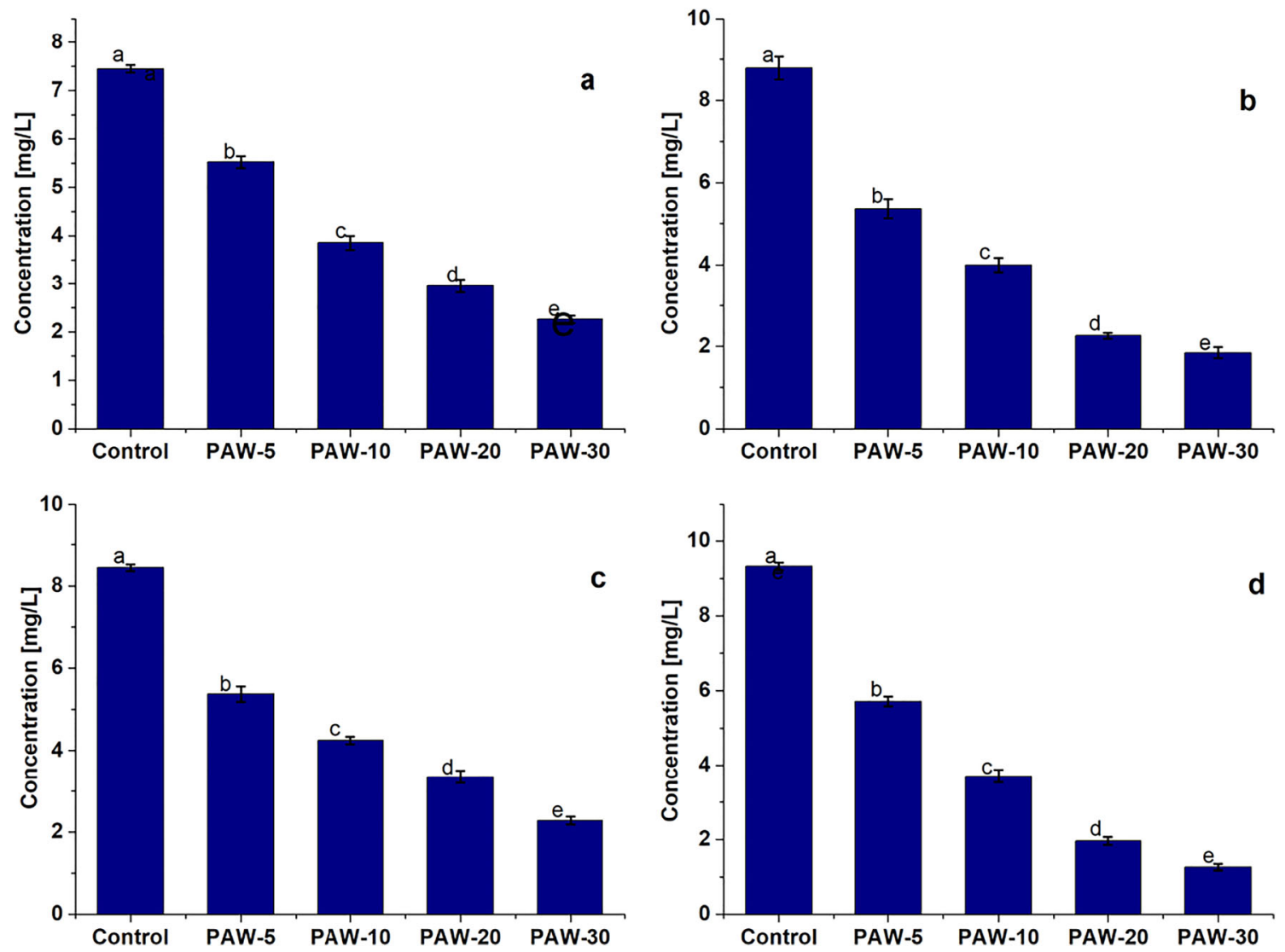

Fig. 5 The concentration of pesticide residues on fruits after exposure to plasma activated for $10 \mathrm{~min}$. a Chlorpyrifos residues on strawberries. b Chlorpyrifos residues on grapes. c Carbaryl residues on strawberries. d Carbaryl residues on strawberries. Mean values $(n=3)$ with the different

(Lozowicka et al. 2016). The high degradation rates obtained in this work are due to the effective generation of large quantities of active species such as $\mathrm{H}_{2} \mathrm{O}_{2}, \mathrm{NO}_{2}$, and $\mathrm{NO}_{3}$. These species react selectively with certain functional groups specifically attacking the high electron density carbon double bond, activated aromatic acid, and non-protonated amines (Mousavi et al. 2016). Lukes et al. (2012) reported that the reactive nitrogen species generated during air-water plasma treatment can also react with pesticides leading to the formation of nitration and nitrozation compounds. The degradation of a contaminant by plasma is reported to depend on many factors such as the target's concentration, sample volume, electrode gap, sample chemistry, reactor type, discharge gas, and sample viscosity (Gao et al. 2013).

To understand the reduction mechanism of pesticide residues on grapes and strawberries, GC-MS/MS was employed to analyze the transformation products. It was observed from several intermediate products which were identified in MS/MS spectra and were further analyzed by comparison with the literature to identify their molecular structures. It cannot be overruled that the degradation pathways of these intermediate products may follow multiple routes due to presence of several reactive sites in the parent

superscript letters are significantly different $(p<0.05)$ and with the same superscript letters are not significantly different $(p \geq 0.05)$. Note: PAW-5, PAW-10, PAW-20, and PAW-30 refer to plasma-activated water (PAW) subjected to plasma treatment for $5,10,20$, and 30 min respectively

compound but in this study, the occurrence of oxidation mechanisms was only proposed. The intermediate compounds identified on reaction of carbaryl with PAW were 1,2-napthoquione, 1,4-napthaoquinone, and 2-hydroxy1,4-napthoquinone. Based on the identified intermediate compounds, a degradation pathway is proposed and presented in Fig. 6. The oxidation of carbaryl into naphthoquinones is likely a subsequent reaction with reactive nitrogen and oxygen species. During PAW treatment, the carbaryl residues under highly oxidative environment undergo hemolytic cleavage of carbon oxygen bonds to produce napthoxyl radicals (Brahmia and Richard 2003). The reactive oxygen species particularly superoxide anions or peroxyradicals combine with radical cations or with 1-nathoxy radicals (IV) to from naphthoquinones (III) (Xu 2000). The mechanism of degradation involved direct attacks of hydroxyl radicals or hydrogen peroxide on benzene rings of carbaryl leading to the formation of hydroxylated products (II) and other carboxylic acids. Furthermore, the hydroxy-1,4napthoquinone compounds identified are likely to secondary oxidation products arising from 1,4-nathoquinone. Similar fragments were also identified as degradation products of carbaryl upon photolysis (Xu 2000). 


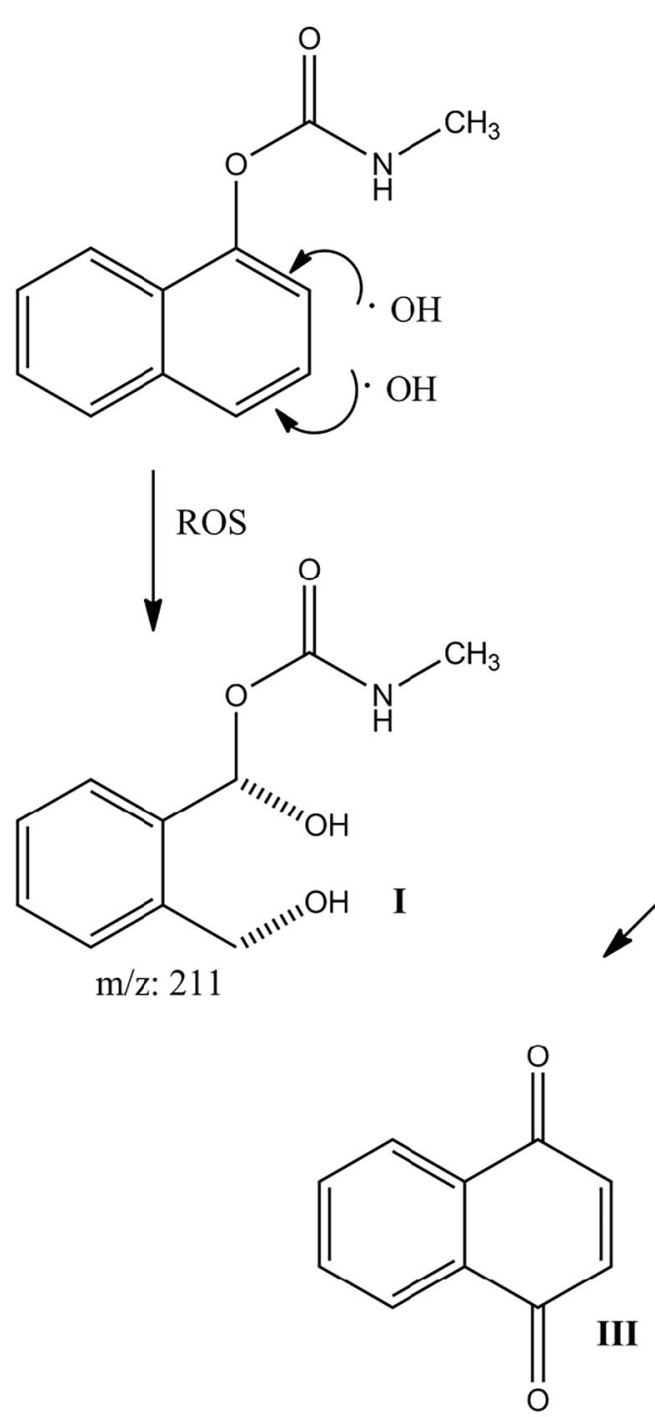

$\mathrm{m} / \mathrm{z}: 158$

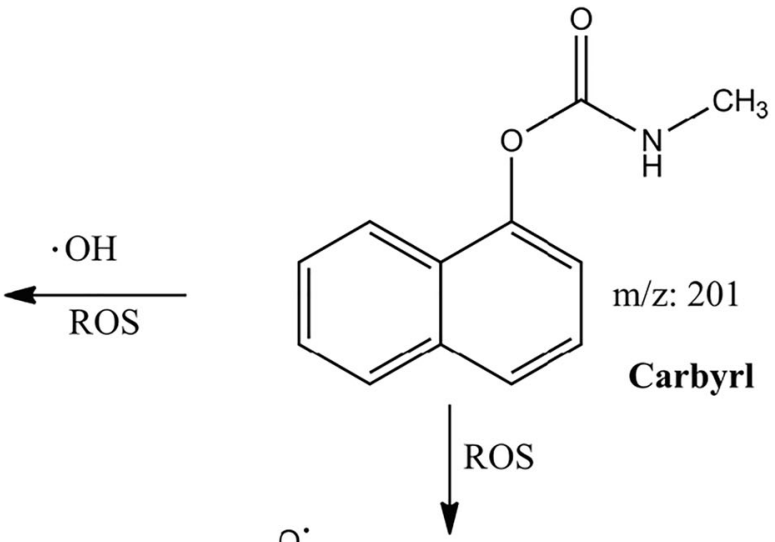<smiles>CNC=O</smiles>

1,4-naphthoquinone

Fig. 6 Proposed degradation pathway of carbaryl

These authors proposed chlorpyrifos degradation was primarily dependent on exposure to PAW. Several transformation products of chlorpyrifos were identified in MS/ MS spectrum and proposed pathway is presented in Fig. 7. The reaction pathway followed was similar to that of other organophosphorus pesticides such as malathion and parathion containing $S=P$. Firstly, oxidation species destroy $\mathrm{S}=\mathrm{P}$ double of chlorpyrifos to form $\mathrm{P}=\mathrm{O}$. This substitution reactions with phosphoryl group $(\mathrm{P}=\mathrm{O})$ lead to formation of chlorpyrifos oxon (II). Further oxidation of chlorpyrifos oxon dissociated into fragments of 3,5,6trichloropyridinol (III) and 3,5,6-trichloro-2-pyridinol (IV). These products were further fragmented to form diethyl phosphate (V) and diethyl phosphorothioate (VI). Similar pathway has been proposed by Zheng et al. (2019) on reduction of phoxim residues on grape by plasmaactivated water. Several authors have also reported oxidation of organophophate pesticides by breaking $\mathrm{P}=\mathrm{S}, \mathrm{S}-\mathrm{P}$, and $\mathrm{S}-\mathrm{C}$ bonds of pesticide molecules by active species such as atomic oxygen and hydroxyl radicals on radio frequency plasma jet treatment (Bai et al. 2010; Zhu et al. 2010). These authors report that the oxidation of pesticides involved by ROS attack. Likewise to the present study, Ranjitha Gracy et al. (2019) also identified similar degraded products on low-pressure non-thermal DBD plasma treatment for chlorpyrifos reduction on tomatoes. Their findings agree with current study regarding presence of ROS in both PAW and plasma discharge as observed in OES. Accordingly, we believe the contribution of PAW to pesticide degradation mainly depends on 


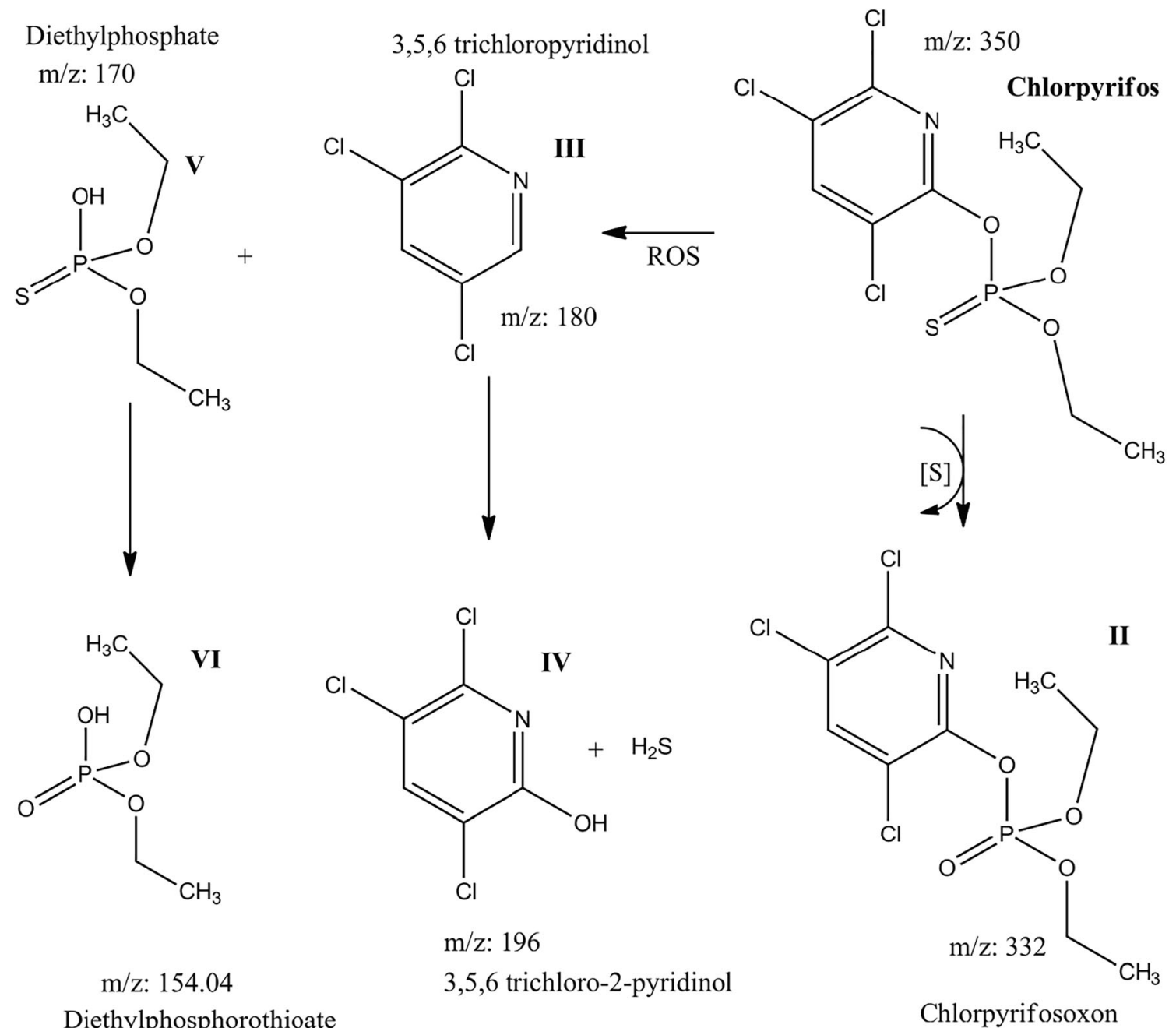

Fig. 7 Proposed degradation pathway of chlorpyrifos

the outstanding capability of ROS to destroy the pesticide molecule by its abundant oxidation capability.

\section{Evaluation of Quality Parameters}

The effect of PAW on the visual appearance, that is, surface color was assessed. It was observed from a visual inspection that there were no signs of physical damage or visual change in either the color of the treated grapes or strawberries. The instrumental color analysis showed (Table 1) a slight decrease in the lightness of strawberries; however, the changes were not significant when compared with the control samples. Such changes in color parameters are attributed to the presence of strong acids and oxidizing agents such as $\mathrm{H}_{2} \mathrm{O}_{2}$ which can react with surface carotenoids and phenolics. Zheng et al. (2019) also demonstrated no significant color changes after PAW treatment of grapes. These results agree with our previous work that direct cold plasma treatment for short exposures resulted to no significant changes in the color of strawberries and cherry tomatoes.

The firmness of PAW-treated grapes and strawberries is presented in Table 1. A significant decrease $(p<0.05)$ in the firmness was observed between the control and PAW 30-min treated sample. The firmness value of the strawberry control sample was found to be $3.8 \mathrm{~N}$ and $1.76 \mathrm{~N}$ for grapes respectively. Firmness of both samples significantly decreased for both PAW 30-min treated samples. Similar decreases in firmness were reported in the direct plasma treatment of cherry tomatoes and blueberries (Lacombe et al. 2015; Misra et al. 2014b). This decrease in firmness is attributed to a surface softening or damage to external cells (Tappi et al. 2016). A study by Lacombe et al. (2015) reported on the loss of firmness for dry air plasma-treated blueberries which was attributed to a mechanical damage and/or an increase in temperature during treatment. However, there was no increase in the PAW temperature as this study was not carried out in situ. There was a significant increase $(p<0.05)$ in TSS values which were 
Table 1 Physical quality parameters (color and firmness) of PAW-treated fruit

\begin{tabular}{lllllll}
\hline & $L^{*}$ & $a^{*}$ & $b^{*}$ & Firmness $(\mathrm{N})$ & Total soluble solids $\left({ }^{\circ}\right.$ Brix $)$ & Titratable acidity $(\%)$ \\
\hline Strawberries & & & & & \\
Control & $41.45 \pm 1.34^{\mathrm{a}}$ & $38.45 \pm 1.44^{\mathrm{a}}$ & $25 \pm 0.98^{\mathrm{a}}$ & $3.89 \pm 0.11^{\mathrm{a}}$ & $8.60 \pm 0.32^{\mathrm{a}}$ & $0.525 \pm 0.03^{\mathrm{a}}$ \\
PAW-5 & $42.43 \pm 1.45^{\mathrm{a}}$ & $38.12 \pm 0.74^{\mathrm{a}}$ & $24.56 \pm 0.45^{\mathrm{a}}$ & $3.76 \pm 0.76^{\mathrm{a}}$ & $8.84 \pm 0.12^{\mathrm{a}}$ & $0.535 \pm 0.05^{\mathrm{a}}$ \\
PAW-10 & $40.95 \pm 0.79^{\mathrm{a}}$ & $37.97 \pm 2.09^{\mathrm{a}}$ & $23.45 \pm 1.78^{\mathrm{a}}$ & $3.78 \pm 0.67^{\mathrm{a}}$ & $8.95 \pm 0.21^{\mathrm{a}}$ & $0.524 \pm 0.12^{\mathrm{a}}$ \\
PAW-20 & $40.14 \pm 2.34^{\mathrm{a}}$ & $38.12 \pm 1.87^{\mathrm{a}}$ & $23.45 \pm 1.34^{\mathrm{a}}$ & $3.56 \pm 0.12^{\mathrm{a}}$ & $9.30 \pm 0.32^{\mathrm{b}}$ & $0.582 \pm 0.12^{\mathrm{a}}$ \\
PAW-30 & $39.45 \pm 0.97^{\mathrm{a}}$ & $37.56 \pm 1.78^{\mathrm{a}}$ & $24.01 \pm 1.56^{\mathrm{b}}$ & $3.36 \pm 0.11^{\mathrm{b}}$ & $9.56 \pm 0.44^{\mathrm{b}}$ & $0.593 \pm 0.32^{\mathrm{a}}$ \\
Grapes & & & & & $0.499 \pm 0.32^{\mathrm{a}}$ \\
Control & $39.45 \pm 1.72^{\mathrm{a}}$ & $25.67 \pm 0.67^{\mathrm{a}}$ & $8.36 \pm 0.98^{\mathrm{a}}$ & $1.76 \pm 0.11^{\mathrm{a}}$ & $15.34 \pm 0.32^{\mathrm{a}}$ & $0.511 \pm 0.12^{\mathrm{a}}$ \\
PAW-5 & $37.57 \pm 1.09^{\mathrm{a}}$ & $24.78 \pm 1.56^{\mathrm{a}}$ & $8.26 \pm 0.25^{\mathrm{a}}$ & $1.62 \pm 0.76^{\mathrm{b}}$ & $15.26 \pm 0.44^{\mathrm{a}}$ & $0.542 \pm 0.25^{\mathrm{a}}$ \\
PAW-10 & $38.56 \pm 0.98^{\mathrm{a}}$ & $25.67 \pm 2.13^{\mathrm{a}}$ & $8.78 \pm 0.85^{\mathrm{a}}$ & $1.54 \pm 0.67^{\mathrm{bc}}$ & $16.23 \pm 0.24^{\mathrm{b}}$ & $0.543 \pm 0.15^{\mathrm{a}}$ \\
PAW-20 & $38.54 \pm 1.11^{\mathrm{a}}$ & $25.56 \pm 1.67^{\mathrm{a}}$ & $8.56 \pm 2.41^{\mathrm{a}}$ & $1.45 \pm 0.12^{\mathrm{c}}$ & $16.46 \pm 0.36^{\mathrm{b}}$ & $0.552 \pm 0.54^{\mathrm{a}}$ \\
PAW-30 & $38.13 \pm 0.97^{\mathrm{a}}$ & $24.45 \pm 0.99^{\mathrm{a}}$ & $8.46 \pm 1.02^{\mathrm{a}}$ & $1.29 \pm 0.11^{\mathrm{d}}$ & $16.76 \pm 0.52^{\mathrm{b}}$ & \\
\hline
\end{tabular}

All the data are expressed as mean \pm standard deviation. Mean values $(n=3)$ with the different superscript letters differ significantly $(p<0.05)$

Fig. 8 Changes in total phenolic content a strawberries and $\mathbf{b}$ grapes after treatment after exposure to plasma activated for $10 \mathrm{~min}$. Mean values $(n=3)$ with the different superscript letters are significantly different $(p<0.05)$ and with the same superscript letters are not significantly different $(p \geq 0.05)$. Note: PAW5, PAW-10, PAW-20, and PAW30 refer to plasma-activated water (PAW) subjected to plasma treatment for 5, 10, 20, and $30 \mathrm{~min}$ respectively
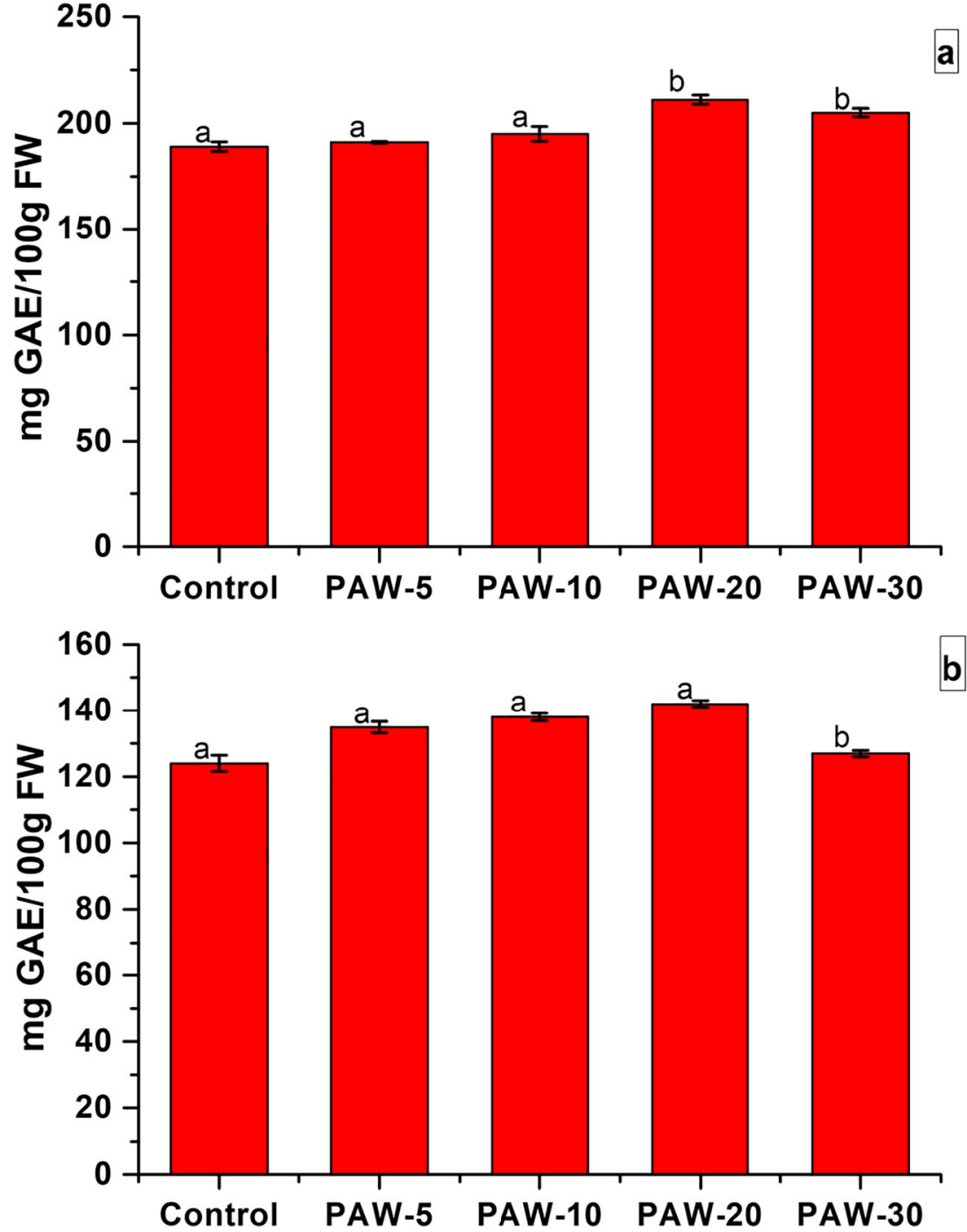
observed in PAW-treated and control samples. The TSS value of fruit samples was enhanced post plasma treatment with the highest value of 9.56 and $16.76^{\circ}$ Brix for strawberries and grapes, respectively, after exposure to PAW $30 \mathrm{~min}$ for 10 min. It was also observed that there was no significant difference $(p>0.05)$ for titratable acidity (TA) in the PAW-treated samples. Similarly, Alencar et al. (2013) found no significant differences for titratable acidity in control and in ozonated water-treated bananas.

Figure 8 shows the changes in the total phenolic content (TPC) of the PAW-treated strawberries and grapes. The TPC of both samples increased significantly $(p<$ 0.05 ) for the PAW-20-treated sample compared with the untreated samples. There was a slight reduction in TPC of
PAW-20 samples for strawberries. However, no significant decreases were found for the grapes. The results in this study agree with reports of Sarangapani et al. (2017c) and Zheng et al. (2019), where the authors also reported a reduction of TPC of blueberries exposed to direct plasma treatment. The increase in TPC can be attributed to the activation of the key enzymes in the synthesis of phenolic compounds (Wang et al. 2012). Another study attributed the activation of the phenylalanine ammonialyase enzyme in fruits to the observed variations in the phenolic content of the treated fruits (Brandenburg et al. 2007). Exposure to a rich oxidative environment can lead to depolymerization and dissolution of cell wall polysaccharides, which facilitates higher extraction or degradation of the
Fig. 9 Changes in total flavonoid content a strawberries and $\mathbf{b}$ grapes after treatment after exposure to plasma activated for 10 min. Mean values $(n=3)$ with the different superscript letters are significantly different $(p<0.05)$ and with the same superscript letters are not significantly different $(p \geq 0.05)$
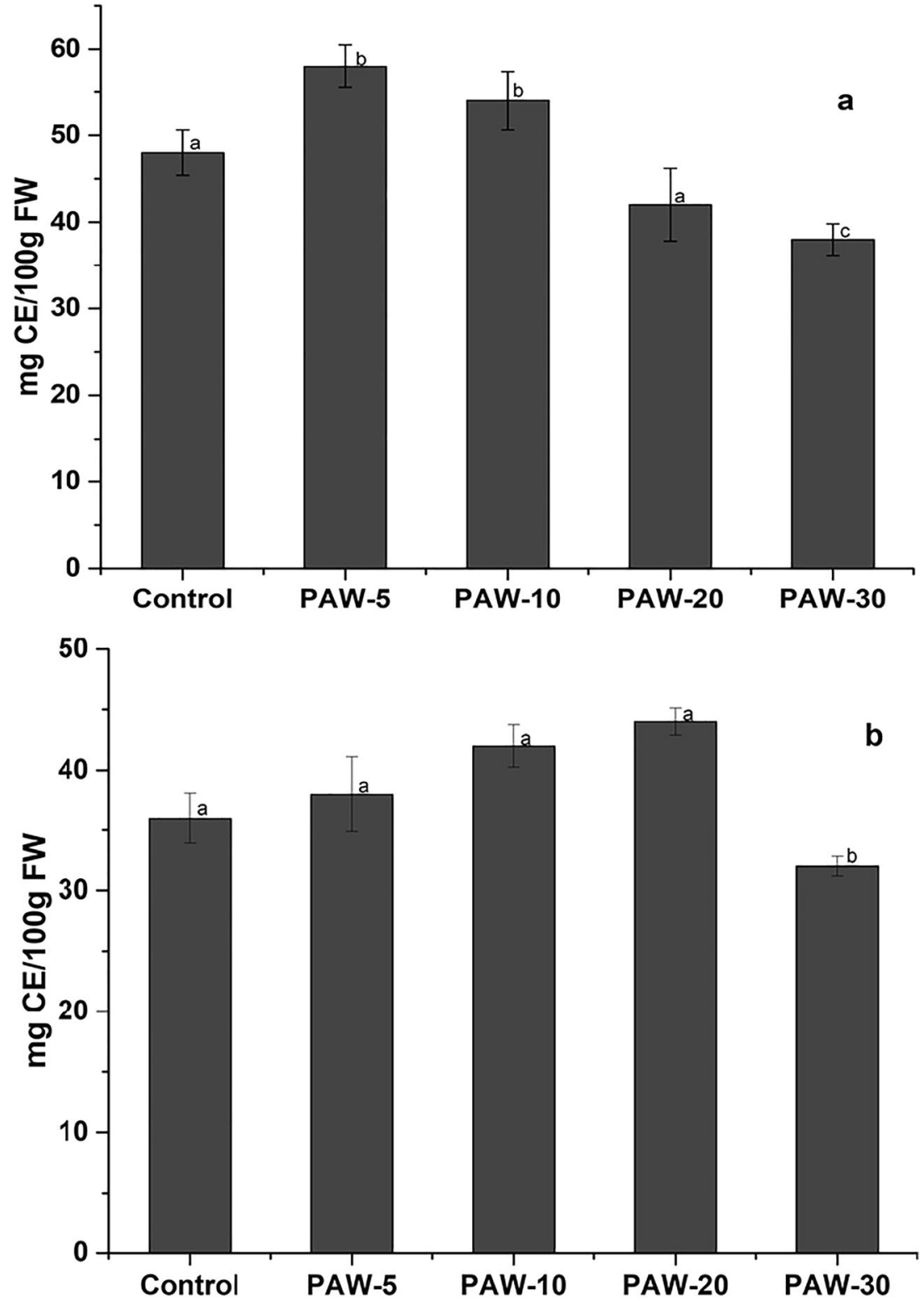
conjugated phenolic compounds (Alothman et al. 2010; Grzegorzewski et al. 2011). A significant variation in total flavonoid content was observed for strawberries (see Fig. 9); however, no significant difference in TFC was observed after PAW treatment of grapes.

Ascorbic acid is considered one of the important nutritional parameters of fresh fruits. The ascorbic acid contents of the control and PAW-treated samples are shown in Fig. 10. Increasing PAW exposure time induced significant effects ( $p$ $<0.05$ ) on the ascorbic acid content of the strawberries. The ascorbic acid content of the control was $25.01 \mathrm{mg} / 100 \mathrm{~g}$, whereas exposure to PAW-30 decreased the content to 18.5 $\mathrm{mg} / 100 \mathrm{~g}$. There was no significant difference in ascorbic content of the grape samples due to the fruit's protective skin. Many authors have reported that ascorbic acid is thermolabile and highly sensitive to various processing and storage conditions (Tiwari et al. 2008). Plasma treatment induces similar losses ascorbic acid in cut carrots, cucumbers, and pears (Wang et al. 2012).

\section{Conclusion}

The results obtained from this study indicate that PAW can significantly degrade pesticides on grapes and strawberries. The degradation of pesticides was found to be dependent on the chemical structure of the pesticide and also the surface properties of the fruit. The maximum pesticide degradation achieved was $86 \%$ for carbaryl and $74 \%$ for chlorpyrifos on the grape samples with a slightly lower degradation achieved for strawberries. The degradation of the pesticides is attributed to the chemical-induced effects of the reactive species (e.g., nitrites, nitrates, and hydrogen peroxide) and high oxidation potential of PAW. No adverse changes were observed in the nutritional quality of the tested samples. In conclusion, these results indicated that PAW can be potential active wash water technology for fruit processing and could replace existing chemical washes. The approach may also offer the additional benefits of produce safety and shelf-life extension due to the known anti-microbial nature of PAW. Future studies should
Fig. 10 Changes in ascorbic acid content a strawberries and $\mathbf{b}$ grapes after treatment after exposure to plasma activated for 10 min. Mean values $(n=3)$ with the different superscript letters are significantly different $(p<0.05)$ and with the same superscript letters are not significantly different $(p \geq 0.05)$. Note: PAW5, PAW-10, PAW-20, and PAW30 refer to plasma-activated water (PAW) subjected to plasma treatment for 5, 10, 20, and $30 \mathrm{~min}$ respectively
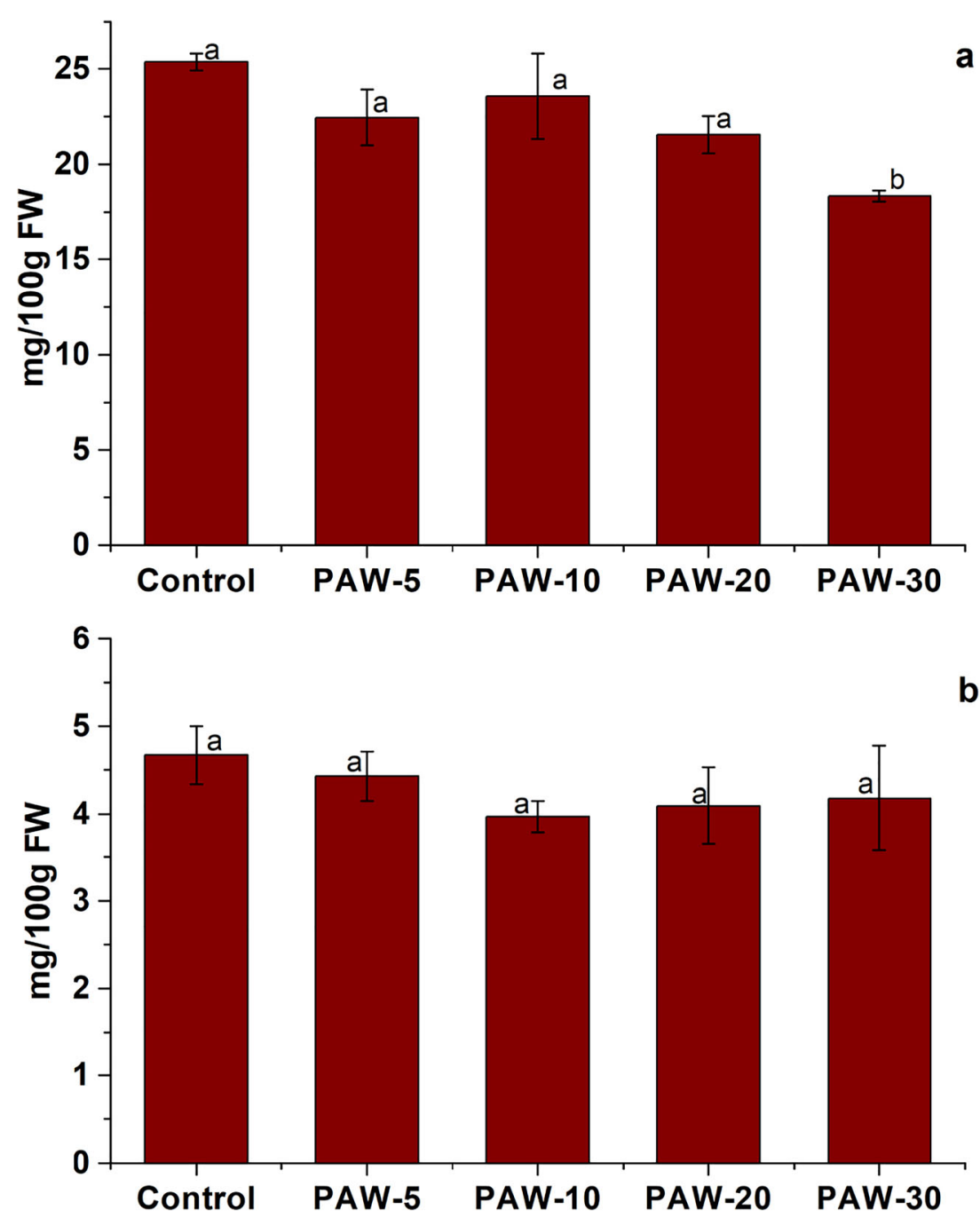
focus on evaluating the decontamination efficacy of the technology over a wider range of pesticides, including combinations of pesticides on different food commodities.

Funding Information The authors received funding from Science Foundation Ireland

\section{Compliance with Ethical Standards}

Conflict of Interest Author PJ Cullen is the CEO of PlasmaLeap Technologies, the supplier of the plasma technology employed in this study.

\section{References}

Alencar, E. R. d., Faroni, L. R. D. A., Pinto, M. d. S., Costa, A. R. d., \& Silva, T. A. d. (2013). Postharvest quality of ozonized "nanicão" cv. bananas. Revista Ciência Agronômica, 44(1), 107-114.

Allwood, P. B., Malik, Y. S., Hedberg, C. W., \& Goyal, S. M. (2004). Effect of temperature and sanitizers on the survival of feline calicivirus, Escherichia coli, and F-specific coliphage MS2 on leafy salad vegetables. Journal of Food Protection, 67(7), 1451-1456.

Alothman, M., Kaur, B., Fazilah, A., Bhat, R., \& Karim, A. A. (2010). Ozone-induced changes of antioxidant capacity of fresh-cut tropical fruits. Innovative Food Science \& Emerging Technologies, 11(4), 666-671.

Bai, Y., Chen, J., Yang, Y., Guo, L., \& Zhang, C. (2010). Degradation of organophosphorus pesticide induced by oxygen plasma: effects of operating parameters and reaction mechanisms. Chemosphere, 81(3), 408-414.

Boehm, D., Heslin, C., Cullen, P. J., \& Bourke, P. (2016). Cytotoxic and mutagenic potential of solutions exposed to cold atmospheric plasma. Scientific Reports, 6(1), 21464.

Bourke, P., Ziuzina, D., Han, L., Cullen, P., \& Gilmore, B. (2017). Microbiological interactions with cold plasma. Journal of Applied Microbiology, 123(2), 308-324.

Brahmia, O., \& Richard, C. (2003). Phototransformation of carbaryl in aqueous solution: laser-flash photolysis and steady-state studies. Journal of Photochemistry and Photobiology A: Chemistry, 156(13), 9-14.

Brandenburg, R., Ehlbeck, J., Stieber, M., v. Woedtke, T., Zeymer, J., Schlüter, O., et al. (2007). Antimicrobial treatment of heat sensitive materials by means of atmospheric pressure Rf-driven plasma jet. Contributions to Plasma Physics, 47(1-2), 72-79.

Feng, X., Ma, X., Liu, H., Xie, J., He, C., \& Fan, R. (2019). Argon plasma effects on maize: pesticides degradation and quality changes. Journal of the Science of Food and Agriculture, 99(12), 5491-5498.

Fett, W. (2002). Factors affecting the efficacy of chlorine against Esherichia coli O157: $\mathrm{H} 7$ and Salmonella on alfalfa seed. Food Microbiology, 19(2-3), 135-149.

Gao, L., Sun, L., Wan, S., Yu, Z., \& Li, M. (2013). Degradation kinetics and mechanism of emerging contaminants in water by dielectric barrier discharge non-thermal plasma: the case of $17 \beta$-Estradiol. Chemical Engineering Journal, 228, 790-798.

Grzegorzewski, F., Ehlbeck, J., Schlüter, O., Kroh, L. W., \& Rohn, S. (2011). Treating lamb's lettuce with a cold plasma-Influence of atmospheric pressure Ar plasma immanent species on the phenolic profile of Valerianella locusta. LWT-Food Science and Technology, 44(10), 2285-2289.

Han, X., Balakrishnan, V. K., vanLoon, G. W., \& Buncel, E. (2006). Degradation of the pesticide fenitrothion as mediated by cationic surfactants and $\alpha$-nucleophilic reagents. Langmuir, 22(21), 90099017.

Jiang, B., Zheng, J., Qiu, S., Wu, M., Zhang, Q., Yan, Z., \& Xue, Q. (2014). Review on electrical discharge plasma technology for wastewater remediation. Chemical Engineering Journal, 236, 348-368.

Kamrin, M. A. (1997). Pesticide profiles: toxicity, environmental impact, and fate: CRC press.

Lacombe, A., Niemira, B. A., Gurtler, J. B., Fan, X., Sites, J., Boyd, G., \& Chen, H. (2015). Atmospheric cold plasma inactivation of aerobic microorganisms on blueberries and effects on quality attributes. Food Microbiology, 46, 479-484.

Lozowicka, B., Jankowska, M., Hrynko, I., \& Kaczynski, P. (2016). Removal of 16 pesticide residues from strawberries by washing with tap and ozone water, ultrasonic cleaning and boiling. Environmental Monitoring and Assessment, 188(1), 51.

Lu, P., Boehm, D., Bourke, P., \& Cullen, P. J. (2017). Achieving reactive species specificity within plasma-activated water through selective generation using air spark and glow discharges. Plasma Processes and Polymers, 14(8), 1600207.

Lukes, P., Locke, B. R., \& Brisset, J.-L. (2012). Aqueous-phase chemistry of electrical discharge plasma in water and in gas-liquid environments. Plasma chemistry and catalysis in gases and liquids, 1, 243308.

Misra, N., Pankaj, S. K., Walsh, T., O’Regan, F., Bourke, P., \& Cullen, P. J. (2014a). In-package nonthermal plasma degradation of pesticides on fresh produce. Journal of Hazardous Materials, 271, 33-40.

Misra, N., Patil, S., Moiseev, T., Bourke, P., Mosnier, J., Keener, K., et al. (2014b). In-package atmospheric pressure cold plasma treatment of strawberries. Journal of Food Engineering, 125, 131-138.

Misra, N., Pankaj, S., Frias, J., Keener, K., \& Cullen, P. (2015). The effects of nonthermal plasma on chemical quality of strawberries. Postharvest Biology and Technology, 110, 197-202.

Mousavi, S. M., Imani, S., Dorranian, D., Larijani, K., \& Shojaee, M. (2016). Effect of cold plasma on degradation of organophosphorus pesticides used on some agricultural products. Journal of Plant Protection Research, 57(1), 25-35.

Phan, K. T. K., Phan, H. T., Boonyawan, D., Intipunya, P., Brennan, C. S., Regenstein, J. M., \& Phimolsiripol, Y. (2018). Non-thermal plasma for elimination of pesticide residues in mango. Innovative Food Science \& Emerging Technologies, 48, 164-171.

Picart-Palmade, L., Cunault, C., Chevalier-Lucia, D., Belleville, M.-P., \& Marchesseau, S. (2018). Potentialities and limits of some nonthermal technologies to improve sustainability of food processing. Frontiers in Nutrition, 5.

Ranjitha Gracy, T. K., Gupta, V., \& Mahendran, R. (2019). Influence of low-pressure nonthermal dielectric barrier discharge plasma on chlorpyrifos reduction in tomatoes. Journal of Food Process Engineering, 42(6), e13242.

Sarangapani, C., Misra, N., Milosavljevic, V., Bourke, P., O’Regan, F., \& Cullen, P. (2016). Pesticide degradation in water using atmospheric air cold plasma. Journal of Water Process Engineering, 9, 225-232.

Sarangapani, C., Danaher, M., Tiwari, B., Lu, P., Bourke, P., \& Cullen, P. (2017a). Efficacy and mechanistic insigh Endocrine Disruptor degradation using atmospheric air plasma.

Sarangapani, C., Devi, R. Y., Thirumdas, R., Trimukhe, A. M., Deshmukh, R. R., \& Annapure, U. S. (2017b). Physico-chemical properties of low-pressure plasma treated black gram. LWT- Food Science and Technology, 79, 102-110.

Sarangapani, C., O'Toole, G., Cullen, P., \& Bourke, P. (2017c). Atmospheric cold plasma dissipation efficiency of agrochemicals on blueberries. Innovative Food Science \& Emerging Technologies, 44, 235-241.

Sarangapani, C., Lu, P., Behan, P., Bourke, P., \& Cullen, P. (2018a). Humic acid and trihalomethane breakdown with potential byproduct formations for atmospheric air plasma water treatment. Journal of Industrial and Engineering Chemistry, 59, 350-361. 
Sarangapani, C., Patange, A., Bourke, P., Keener, K., \& Cullen, P. (2018b). Recent advances in the application of cold plasma technology in foods. Annual Review of Food Science and Technology, 9(1), 609-629.

Sarangapani, C., Ziuzina, D., Behan, P., Boehm, D., Gilmore, B. F., Cullen, P., et al. (2019). Degradation kinetics of cold plasmatreated antibiotics and their antimicrobial activity. Scientific Reports, 9(1), 3955.

Scally, L., Gulan, M., Weigang, L., Cullen, P., \& Milosavljevic, V. (2018). Significance of a non-thermal plasma treatment on LDPE biodegradation with Pseudomonas Aeruginosa. Materials, 11(10), 1925.

Selma, M. V., Beltrán, D., Allende, A., Chacón-Vera, E., \& Gil, M. I. (2007). Elimination by ozone of Shigella sonnei in shredded lettuce and water. Food Microbiology, 24(5), 492-499.

Singleton, V. L., Orthofer, R., \& Lamuela-Raventós, R. M. (1999). Analysis of total phenols and other oxidation substrates and antioxidants by means of folin-ciocalteu reagent. Methods in enzymology, 299, 152-178.

Tappi, S., Gozzi, G., Vannini, L., Berardinelli, A., Romani, S., Ragni, L., \& Rocculi, P. (2016). Cold plasma treatment for fresh-cut melon stabilization. Innovative Food Science \& Emerging Technologies, 33, 225-233.

Thirumdas, R., Sarangapani, C., \& Annapure, U. S. (2015). Cold plasma: a novel non-thermal technology for food processing. Food Biophysics, 10(1), 1-11.

Thirumdas, R., Kothakota, A., Annapure, U., Siliveru, K., Blundell, R., Gatt, R., \& Valdramidis, V. P. (2018). Plasma activated water (PAW): chemistry, physico-chemical properties, applications in food and agriculture. Trends in Food Science \& Technology, 77, 21-31.

Tiwari, B. K., Muthukumarappan, K., O’Donnell, C. P., \& Cullen, P. (2008). Kinetics of freshly squeezed orange juice quality changes during ozone processing. Journal of Agricultural and Food Chemistry, 56(15), 6416-6422.

Wang, R., Nian, W., Wu, H., Feng, H., Zhang, K., Zhang, J., et al. (2012). Atmospheric-pressure cold plasma treatment of contaminated fresh fruit and vegetable slices: inactivation and physiochemical properties evaluation. The European Physical Journal D, 66(10), 276.

Xu, S. (2000). Environmental fate of carbaryl. Sacramento: California Environmental Protection Agency, Department of Pesticide Regulation.

Yuk, H. G., Yoo, M. Y., Yoon, J. W., Moon, K. D., Marshall, D. L., \& Oh, D. H. (2006). Effect of combined ozone and organic acid treatment for control of Escherichia coli O157: H7 and Listeria monocytogenes on lettuce. Journal of Food Science, 71(3), M83M87.

Zheng, Y., Wu, S., Dang, J., Wang, S., Liu, Z., Fang, J., Han, P., \& Zhang, J. (2019). Reduction of phoxim pesticide residues from grapes by atmospheric pressure non-thermal air plasma activated water. Journal of Hazardous Materials, 377, 98-105.

Zhishen, J., Mengcheng, T., \& Jianming, W. (1999). The determination of flavonoid contents in mulberry and their scavenging effects on superoxide radicals. Food Chemistry, 64(4), 555-559.

Zhu, W.-C., Wang, B.-R., Xi, H.-L., \& Pu, Y.-K. (2010). Decontamination of VX surrogate malathion by atmospheric pressure radio-frequency plasma jet. Plasma Chemistry and Plasma Processing, 30(3), 381-389.

Ziuzina, D., Patil, S., Cullen, P. J., Keener, K., \& Bourke, P. (2014). Atmospheric cold plasma inactivation of Escherichia coli, Salmonella enterica serovar Typhimurium and Listeria monocytogenes inoculated on fresh produce. Food Microbiology, 42, 109-116.

Publisher's Note Springer Nature remains neutral with regard to jurisdictional claims in published maps and institutional affiliations. 